\title{
ADVANTAGES OF PROPOSITIONALISM
}

BY

NEIL SINHABABU

\begin{abstract}
Propositionalism is the view that the contents of intentional attitudes have a propositional structure. Objectualism opposes propositionalism in allowing the contents of these attitudes to be ordinary objects or properties. Philosophers including Talbot Brewer, Paul Thagard, Michelle Montague, and Alex Grzankowski attack propositionalism about such attitudes as desire, liking, and fearing. This article defends propositionalism, mainly on grounds that it better supports psychological explanations.
\end{abstract}

We can describe what people desire in two different ways. Sometimes 'desire' takes a sentential complement that includes a verb, as in 'Jenny desires that she eat chocolate.' This suggests propositionalism about desire, on which the content of Jenny's desire involves the relation of eating indicated by the verb 'eat'. The content could be the proposition that she eats chocolate or a state of affairs in which she eats chocolate. Sometimes 'desire' simply takes a noun as a complement, as in 'Jenny desires chocolate.' This suggests objectualism about desire, according to which the content of Jenny's desire need not include the relation of eating, and could be chocolate itself or the property of being chocolate.

While propositionalism is the orthodox view about many kinds of attitudes including belief and desire, it has recently found many opponents. Talbot Brewer's 'Three Dogmas of Desire" and Paul Thagard's 'Desires Are Not Propositional Attitudes, ${ }^{2}$ attack propositionalism about desire. Michelle Montague's 'Against Propositionalism'3 and Alex Grzankowski's 'Not All Attitudes are Propositional' attack propositionalism about liking and other attitudes. ${ }^{4}$ Trenton Merricks writes of Brewer and Montague, 'I find their arguments persuasive. ${ }^{5}$

This article responds to Brewer, Thagard, Montague, and Grzankowski by illustrating the advantages of propositionalism about psychological states.

Pacific Philosophical Quarterly ••(2015) ••-• DOI: 10.1111/papq.12070

(C) 2015 The Author

Pacific Philosophical Quarterly (C) 2015 University of Southern California and John Wiley \& Sons Ltd. 
After examining their views in more detail, I'll present two considerations favoring propositionalism about desire. First, when people desire to interact differently with the same thing, objectualism incorrectly treats them as desiring the same thing, while propositionalism correctly treats them as desiring different things. Second, propositionalism allows desire to successfully explain action, thought, and feeling, while objectualism doesn't. Propositionalism has similar advantages over objectualism in the cases of liking and fearing. I'll explain why objectualists can't mimic these advantages by dividing desire and liking into many objectual attitudes, and consider how propositionalists might account for the attitudes of missing, mourning, and loving, which objectualists suggest as counterexamples. Then I'll conclude by arguing that the most important issue at stake between propositionalists and objectualists is whether their views can support good psychological explanations. Some of these points have been hinted at before - for example, by Lewis at the beginning of 'Attitudes De Dicto and De Se. ${ }^{6}$ But the burgeoning support for objectualism suggests that hints haven't been enough, and the arguments for propositionalism need to be explicitly presented.

\section{Defenders of objectualism}

I begin by considering how Brewer, Thagard, Montague, and Grzankowski define the propositionalist view they're attacking, and the intentional attitudes they cite as counterexamples to it. They all regard the linguistic structure of intentional attitude attributions as a reason to reject propositionalism.

Brewer criticizes 'the claim that any desire can be expressed fully, without distortion or loss, as a desire that thus-and-such' (p. 260). His criticisms extend to a propositionalist view which doesn't specify a particular metaphysics of intentional objects, but insists that 'the object of any desire is capturable in propositional terms, in the sense that the truth of the relevant proposition is a necessary and sufficient condition for the attainment of the desire's end' (p. 264). He goes beyond the other objectualists in arguing that infinitival desires-to can't be translated into propositional desires-that. As he characterizes the propositionalist view, it may treat desire contents as propositions, states of affairs, or world-sized self-ascribed de se properties of the sort suggested by Lewis. ${ }^{7}$ The important thing is that the conditions under which the desire is satisfied must be the same as those under which the relevant proposition is made true. That's the sort of propositionalist view I'll defend here.

Thagard criticizes Timothy Schroeder's Three Faces of Desire for assuming 'that desires are propositional attitudes' (p. 151). ${ }^{8}$ While he doesn't explore the options for a metaphysics of attitude contents in great detail, his claim that 'desires are directed toward things rather than toward states of 
affairs' fits the other objectualists' description of their position (p. 152). Thagard emphasizes psychological and neuroscientific evidence that many animals can't mentally represent the complex relations that propositional desire-contents would involve. Making the plausible assumption that animal and human hunger have a similar structure, Thagard claims that 'Animals desire food, not that they should have food. Humans are usually the same' (p. 152).

\title{
Montague characterizes propositionalism as:
}

\begin{abstract}
... the view that every intentional attitude is a propositional attitude. On this view, every mental state or event (thought, belief, hope, fear, perception, etc.) that has an object, or is about something, or directed at something, either is or involves an attitude or relation to a proposition or something essentially proposition-like, something that is not just a particular physical object, say, or a particular property. To have an intentional attitude to anything, on this view, is to be related to something that is (so to say) essentially discursive in form, i.e. something whose nature can only be perspicuously conveyed by a verb-involving sentence (p. 503).
\end{abstract}

Montague, like Brewer, criticizes a wide range of propositionalist views which require that intentional attitudes aren't 'objectual attitudes' - that is, attitudes merely directed at ordinary physical objects or properties (p. 504). While Montague accepts that beliefs are propositional attitudes and doesn't directly attack the view that desires are propositional attitudes, she argues that propositionalism fails in other cases, including the 'fundamental pro-attitude - liking' in which she takes all desires to be grounded. On her view, liking chocolate need not merely be an elliptical way of talking about liking to have chocolate. While some likings may be propositional attitudes, she argues, 'vast, chocolatey numbers of them' are objectual attitudes (p. 509). As she recognizes, the interesting question is whether any attitudes are irreducibly objectual. She then considers and rejects several propositionalist strategies for discharging this burden, some of which rest on linguistic evidence for the view, and some of which involve reducing objectual attitudes to propositional attitudes.

Grzankowski holds that 'those who hold that all intentional states are propositional are mistaken' (p. 1). He recognizes that propositionalists may wish to explain objectual attitudes in terms of propositional attitudes, considers two ways in which they might do this, and argues against both of them. On a stronger view ('Propositionalism A'), each objectual attitude can be analyzed in terms of some propositional attitudes. On a weaker view ('Propositionalism B'), 'For every attitudinal relation between a subject and a non-propositional object, there are propositional attitudes (of that subject's) upon which it supervenes' (p. 7). He takes the attitude of liking to be a counterexample to Propositionalism A. Some of his most powerful examples concern the attitude of fearing, which he sees as a counterexample to Propositionalism B, and a fortiori to A as well. 
All these philosophers take it to be an advantage of objectualism that it fits the linguistic structure of many of our intentional attitude attributions. Brewer writes:

... when non-philosophers do make use of the word 'desire,' they tend to use it in one of two ways, both of which philosophers tend either to misinterpret or to ignore entirely. In its most common use, the verb 'desire' carries a direct object, as when I say that I desire a Harley Davidson, or the sylvan fields of my youth, or (and this is probably the verb's most common use) some person. In its next most common use, 'desire' is followed by an infinitive, as when I say that I desire to kindle a friendship, to travel, or to read some author's latest book. There are intuitive reasons for doubting that all such desires can really be translated without loss into the supposedly standard propositional form (p. 263).

Thagard also argues for objectualism with linguistic examples, despite placing greater weight on psychological and neuroscientific evidence: 'Andrew desires a beer. Ron desires ice cream. Brad desires Angelina. The lab rat desires a food pellet' (p. 151). He writes that 'Grammatically, none of these sentences requires a 'that' clause; the object of desire is a thing or kind of thing, not a state of affairs' (p. 151). Similarly, Montague first argues for objectualism with these examples: 'Mary loves Nancy. She seeks the fountain of youth. She has you in mind. She contemplates the sky. And she wants Nancy's car' (p. 507). Because of examples like this, she says, 'The burden of argument is plainly on the propositionalists' (p. 507). And Grzankowski motivates objectualism by listing what seem to be "non-propositional attitudes: I like Sally, my brother fears snakes, everyone loves my grandmother, and Rush Limbaugh hates Obama' (p. 1). He argues 'that things are as they appear: there are non-propositional attitudes' (p. 1).

\section{Propositionalism explains sameness of desire}

We might say of Jenny that she desires chocolate, desires a diamond necklace, desires a goldfish, and desires Johnny Depp. Chocolate, a diamond necklace, a goldfish, and Johnny Depp are concrete objects, not propositions or anything proposition-like. Objectualists note that their view neatly fits these desire-attributions.

We also might say of Jenny that she desires to eat chocolate, wear a diamond necklace, keep a goldfish in her aquarium, and make love to Johnny Depp. One might regard it as a corresponding virtue of propositionalism that it fits these attributions. Then it might seem that objectual and propositional characterizations of desire are equally good.

But propositionalism is superior in picking out the cases where we say that two people desire the same thing. Consider Charles the cannibal, who is motivated to eat Johnny Depp. According to propositionalism, Charles desires 
to eat Johnny Depp. According to objectualism, Charles desires Johnny Depp. According to objectualism, both Jenny and Charles have the same desire, and desire the same thing. But according to propositionalism, they don't have the same desire or desire the same thing. Which way of attributing a sameness in desire is right?

Intuitively, the propositional construal is right and the objectual construal is wrong. It's bizarre to say that Jenny and Charles have the same desire, or desire the same thing. One might say of each of them that they desire Johnny Depp. But since they desire to interact with him in very different ways, it's wrong to say they desire the same thing. Propositionalism characterizes desire in a way that explains when two people genuinely desire the same thing. Objectualism fails to do this, and if we take it as the right way to understand desire, we'll mistakenly attribute a sameness in desire to people whom we intuitively regard as desiring wildly different things.

It seems that objectualism faces this problem for all our desires. We can interact with the things we desire in many ways - eating them, owning them, smoking them, wearing them, causing them to exist, and so forth. It's unclear what it would be to desire an object or property itself, independent of any particular mode of interacting with it (even existing in the same world as it, which has a propositional characterization). Of course, context and our background understanding of the world often allow us to determine which relation to the desired thing is suggested by an objectual desire attribution. When we hear that Jenny desires Johnny Depp, our background expectations lead us to understand that she doesn't desire to eat, wear, or smoke him. But for any desire, we can always look to unusual people like Charles for cases in which objectualism mistakenly presents two people as desiring the same thing.

Objectualists might respond to this case by distinguishing the reasons for which Jenny and Charles desire Johnny Depp. On this response, they both simply desire Johnny Depp, but we don't attribute a sameness in desire to them because they have different reasons for desiring him. Jenny's reason is to make love to him, while Charles' reason is to eat him. The problem with this response is that the best explanation of this difference in reasons invokes propositional desire-contents. Jenny and Charles have different reasons because of some psychological difference between them. Their different reasons for desiring don't just float free from their psychologies. Propositionalism tells us what this psychological difference is: Jenny desires that she make love to him, not that she eat him. The relation to Johnny Depp invoked in her reason comes from the propositional content of her desire. Objectualists can't escape this propositionalist solution by appealing to their different beliefs about him, where Jenny believes he'd be a good lover for her, while Charles believes he'd be a good dinner for him. The different kinds of subjective goodness that their beliefs concern are grounded in their different desires, as differences in the goodness of lovers or meals for different people 
often are. If objectualists invoke reasons and subjective goodness to explain when we attribute a sameness in desire, giving further explanations of those things will push them back into the propositionalist framework.

Brewer argues that propositionalism faces a similar problem in translating infinitival desires-to into propositional desires-that. He writes that that if he desires to go fishing, 'fishing might be lit up for me as good or choiceworthy because of the prospect of catching a tasty trout, or because it would take me up into a beautiful mountain range, or because it would involve wading in the cool rushing waters of mountain streams' (p. 265). Just as objectualism collapses Jenny and Charles' desires, Brewer claims that propositionalism collapses desires to fish that present fishing as good in these different ways. But propositionalism does as well as Brewer's own view in addressing this problem. Tal's desire to fish (translated by the propositionalist as a desire that he fish) is a constitutive means to satisfying his more fundamental desire that he catch a tasty trout, or that he go to a beautiful mountain range, or that he wade in mountain streams. On the infinitival view, distinguishing these desires to fish will similarly require grounding in more fundamental desires-to - otherwise the infinitival view won't distinguish different ways of desiring to fish as Brewer wants. Since the same move solves the problem for both views, there's no special problem for propositionalism here.

It's best to understand objectual desire attributions as a shorthand for propositional desire attributions. We use them for economy of expression when our audience has enough background knowledge to know which propositional content we mean. When our audience wouldn't fill out the rest of the attitude ascription correctly, we use propositional desire attributions. As Lewis suggests, 'the objects of our attitudes are uniform in category, and it is our ways of speaking elliptically about these uniform objects that are diverse' (p. 514). While it'd be nice to have a formula for translating any objectual attitude attribution into propositional form, I can't offer one here. Knowing whether someone who desires Johnny Depp desires that they eat him, make love to him, hire him, or keep him in an aquarium requires background information about the desirer. The best I can say is that desiring $\mathrm{x}$ is desiring that some $\mathrm{x}$-involving state of affairs obtain.

\section{Propositionalism about desire explains behavior, feeling, and thought}

Another advantage of propositionalism about desire is that it allows desires to explain what they're supposed to explain, while objectualism doesn't. Desires are supposed to explain motivation, pleasure, and the direction of attention. ${ }^{9}$ We should prefer accounts of desire that help us clearly and 
correctly specify how someone will act, feel, and think over accounts that don't help us do so. If we regard desire-contents merely as concrete physical objects, we'll fail to understand exactly what Jenny will try to obtain, be pleased by, and attend to news of.

Consider Jenny's desires as previously described. Given the opportunity, Jenny will be motivated to eat chocolate, wear a diamond necklace, keep a goldfish in her aquarium, and make love to Johnny Depp. But she won't be motivated to wear chocolate, eat a diamond necklace, make love to a goldfish, or keep Johnny Depp in her aquarium. Opportunities to achieve the former states of affairs may please her. Opportunities to achieve the latter will not.

Propositionalism separates the states of affairs Jenny will be attracted to in deliberation and action from the ones she won't be attracted to. Objectualism fails to do this. Nothing in the objectual attitude attributions suggests that Jenny will pursue eating chocolate rather than wearing it, or making love to Johnny Depp rather than keeping him in her aquarium. The propositional attitude attributions, however, specify this clearly. In pointing out the modes of interaction with the objects that Jenny will pursue and be pleased by, propositional forms succeed at an explanatory task where objectual forms fail.

Desire-attributions are essential to explaining animal behavior as well. On an objectual construal, Rover desires the meat and desires Lassie. On a propositional construal, Rover desires that he eat the meat and desires that he mate with Lassie. Propositionalism explains why Rover tries to eat the meat and mate with Lassie, but doesn't try to eat Lassie and mate with the meat. Objectualism can't explain this. Thagard doesn't show us how to explain it, despite claiming that 'Taking desires as propositional attitudes is implausible for humans, and even more implausible for animals with more limited representational capacities' (p. 151). He argues that most mammals can't have propositional desires because they lack the capacity for self-representation, as evidenced in mirror-recognition tasks, and can't represent abstract relations like causation. Since propositional desire-contents would involve concepts of these relations and the self, Thagard concludes that these animals can't have them. Humans probably share some animal motivational states like hunger and lust, so this would be a problem for propositionalism about humans too. But as Schroeder argues, Thagard has an overly restrictive idea of what it takes to realize propositional content (p. 166). ${ }^{10}$ On a broad functionalist view, whatever in Rover makes him try to eat the meat rather mating with it or putting it in another dog's mouth is part of what realizes his desire. Even if this doesn't help him do mirror-recognition tasks or abstractly comprehend eating, it makes his desire a desire that he eat the meat. To explain what animals do and don't do, we should accept that propositional desire-content can be realized more easily than Thagard allows. 
Only propositionalism specifies how humans and animals are moved to interact with desired objects, which varies greatly from object to object. ${ }^{11}$ Objectualism doesn't, and this is why it can't support even simple beliefdesire explanations. Propositionalism's advantage in psychological explanation may explain its ability to deliver accurate same-desire attributions. Attributing desires is a good way to explain action, feeling, and thought. ${ }^{12}$ Since the point of attributing mental states is to provide psychological explanations, that two mental states play the same explanatory role may cause us to treat them as the same in our mental-state attributions. If this is right, propositionalism's success in fitting our same-desire attributions is grounded in its success in providing good psychological explanations.

\section{Propositionalism about liking has the same advantages}

Montague and Grzankowski defend objectualism about the attitude of liking. On Montague's view, desire 'is not a primitive intentional attitude, and depends for its existence on there being a fundamental pro-attitude liking - that cannot be given a propositionalist analysis' (p. 509). She cites taste preferences as a familiar example of liking - 'one just likes chocolate, brussel sprouts, Marmite, etc. The same goes for smell, colours, and combinations of colours. One may simply find another person sexually attractive, or not. In a museum, one may find oneself simply liking certain pieces' (p. 509). Grzankowski follows Montague in using 'Everyone likes chocolate' as an example of a good objectual attitude attribution (p. 6). He considers several propositional analyses of liking, and argues that they all fail, taking this as a reason to reject Propositionalism A. As I'll show, both of the arguments against objectualism about desire have force against objectualism about liking. Then I'll address Grzankowski's rejection of the various propositional analyses.

First, people who like different aspects of chocolate shouldn't be regarded as liking the same thing. If Tim likes to taste chocolate and Lou likes to look upon its smooth brown surface, Tim and Lou like different things. We wouldn't describe them as liking the same thing, or as sharing each other's likings.

Here an objectualist might respond that what Tim and Lou like are properties. Tim likes the taste of chocolate, while Lou likes the look of chocolate. Adding to the example addresses this response. Suppose Teresa likes the taste of chocolate and other things that look and taste exactly like chocolate. However, she doesn't like the look of chocolate - she just likes tasting things that look like it. Lisa, on the other hand, likes the look of chocolate and other things that look and taste exactly like chocolate. She doesn't like the taste of chocolate, but only likes looking at things that look and taste like 
it. Intuitively, Tim, Lou, Teresa, and Lisa all like different things. But objectualism can't successfully distinguish all their likings. The same two properties (the taste and look of chocolate) make it the case that Teresa and Lisa like something. The same property (the taste of chocolate) is involved in how Tim and Teresa interact with what they like. So if objectualism defines the object of liking either in terms of the properties that make it the case that something is liked, or in terms of the property the liker interacts with, it'll attribute a sameness in liking to people who like different things. We can distinguish Teresa's likings from the others by specifying that she likes to have the tasting relation to things that taste and look like chocolate. But that's to add the content that a propositional characterization of her liking requires.

Objectualism, furthermore, doesn't allow liking to do the explanatory work that it should. We use the attitude of liking, among other things, to explain when people will be pleased. Perhaps you like chocolate, funny hats, motorcycles, and good dancers. Then you'll be pleased when eating chocolate, wearing funny hats, riding motorcycles down the highway, and dancing with good dancers. But you might not be pleased when wearing chocolate, eating funny hats, dancing with motorcycles, or riding good dancers down the highway. Propositionalism characterizes your likings in a way that allows us to understand when you'll be pleased, while objectualism leads to confusion on this matter.

The objectualist might respond that what you really like are properties the taste of chocolate, the look of a funny hat, the feeling of riding a motorcycle, and the fun of dancing with a good dancer. But how can your likings be distinguished from those of someone who has a sentimental attachment to these properties, and is pleased merely by their being instantiated somewhere in the universe? Situations that please that person may not please you, and nobody would say that the two of you share a liking, or that both of you like the same thing. Propositionalism about liking avoids all these problems, just as in the case of desire.

Grzankowski argues against Propositionalism A by considering a few propositional analyses of liking and showing that they fail. Among these are ' $\mathrm{S}$ likes $y$ iff $\exists F, S$ likes that $y$ is $F$ ' and ' $S$ likes y iff $S$ likes that y causes $S$ (himself) pleasure in some way or other' (p. 9). Grzankowski is right that these analyses aren't promising. But a propositional analysis of liking need not simply be a one-size-fits-all extension of objectual liking attributions, as these analyses are. As in the case of desire, propositionalists may attach different relations to the objectualists' objects - for example, eating in the case of chocolate and wearing in the case of the diamond necklace. The ability to do so is an essential feature of propositionalism, and one that Grzankowski doesn't consider in providing propositional analyses that try to extend every objectual attribution using the same relation (in the first case, instantiation of some property; in the second case, causation of pleasure). To explain why we sometimes use objectual desire attributions in ordinary 
speech, propositionalists can then say that we leave out the relations in cases where our audience can easily fill them in.

As an illustration of what a propositional characterization of liking might look like, consider ' $\mathrm{S}$ likes y iff sensory or imaginative representations that $\mathrm{y}$ cause S pleasure.' Plugging the propositional characterization of liking into this formula gives us the right results about when people would be pleased. If you like riding motorcycles down the highway, sensory representations of doing so will cause you pleasure. This provides a causal explanation of why you feel pleasure when riding motorcycles down the highway - you're pleased by the sensations of zipping down the road as the world flies by. Daydreams about riding motorcycles down the highway, in which you imagine these experiences, will please you as well. But sensory or imaginative representations of eating a motorcycle probably won't please you. This is why objectualist attempts to replace 'that y' with 'of y', where y is some object, will fail. Only representations of some relations to the object will cause pleasure, and only propositionalism makes room for specifying these relations in the attitude content. While this is a propositional characterization of liking, it isn't a formula for turning objectual liking attributions into propositional ones. Just as with desire, substantial background knowledge will be required to fill in the relations involved in liking motorcycles and liking chocolate.

Grzankowski and Montague never offer a full objectual characterization of the functional properties of liking. If they tried to, they might soon realize that objectual attributions of liking won't do the psychological work of explaining when someone will be pleased.

\section{The advantages of propositionalism extend to fearing}

Grzankowski discusses the attitude of fearing (pp. 10-13). Propositionalism naturally fits some fears, such as the fear that one's parents will die. But he sees other fears, like the fear of snakes, as better fitting objectualism. Grzankowski considers two creatures, Adam and Barry, who live identical lives, receiving all the same information and having all the same occurrent mental states, and who haven't encountered snakes. They differ in that Adam's evolutionary history selected for a dispositional fear of snakes, while Barry's evolutionary history didn't. Grzankowski writes that 'All of our best evidence for the presence of propositional attitudes suggests that the creatures are propositionally the same. If there is an unreported or otherwise hidden propositional attitude that accounts for the difference between them, the burden is on the propositionalist to say what it is' (p. 13). The difference, Grzankowski suggests, is that Adam has a fear of snakes that can only be characterized objectually. 
But only propositionalism explains why some relations to snakes will cause fright in Adam, while others won't. As Adam perceives the distance between himself and a snake decreasing, his level of fright will increase. Why would his fright be sensitive to this relation? Adam's level of fright isn't similarly affected by other relations between himself and snakes. His fright doesn't depend on whether he thinks a snake is coiling itself into the shape of the second letter of his name. Explaining why Adam's level of fright responds to the distance relation but not the second letter coiling relation requires a propositional characterization of Adam's fear. For example, we could say that Adam fears being near snakes. (He doesn't fear that snakes will coil themselves into a 'd' shape.) We can only explain his level of fright under different relations to snakes by characterizing his fear in a way that invokes some relations to snakes but not others. Propositionalism leaves room to specify these relations, while objectualism doesn't. So we should attribute an innate propositional fear to Adam - perhaps, a fear of being near snakes.

By this point, the propositionalist strategy should be clear. Propositionalists should consider when a supposedly objectual attitude produces its psychological effects and when it doesn't. If some relations to the object produce effects while others don't, the objectual attitude attribution is probably just an elliptical attribution of a propositional attitude involving only the effect-producing relations. I'll now consider a way for objectualists to respond to this strategy.

\section{Dividing attitude kinds doesn't help objectualists}

Objectualists might respond by dividing attitudes like desire, liking, and fearing into sub-attitudes. (Here I'll discuss desire, but my arguments will apply to liking and fearing mutatis mutandis.) Perhaps the right way to characterize Jenny's attitude towards Johnny Depp isn't merely as a desire, but as a desire-to-make-love-to. This lets us say that she and Charles have different desires. It also explains her behavior and emotions. Her desire doesn't move her to smoke Johnny Depp because it is a desire-to-make-love-to, and this has different effects than a desire-to-smoke. The objectualist strategy here is to take the relation to the object out of the propositional content of the attitude and put it into the kind of attitude. The attitude's content will then simply be an object. This strategy can be used to divide the propositional attitude kind of desiring into many different objectual attitude kinds.

Dividing desire into many desires-to in this fashion dramatically increases the number of attitude kinds we posit. There are many ways to desire something. We have desires to eat, drink, play, wear, buy, own, smoke, ride, hire, live in, and make love to various things and persons. While before we might have thought the list of attitude kinds would be limited to belief, desire, and 
perhaps a few others, this proposal will produce an explosion of attitude kinds. Any hopes for a simple ontology of attitude kinds, which psychology could conveniently systematize, must be abandoned.

Objectualists might respond that their theory, so modified, is no worse than propositionalism in the number of entities it posits. While objectualists have many attitude kinds, propositionalists have many propositions. Why are the propositionalists any better off?

Propositionalists are better off because they stick with entities that everyone is forced to posit by their account of belief. The objectualists I consider here don't offer an objectual account of belief. On their views, we already have to posit propositions or something proposition-like as the content of belief. Propositionalists can use the same entities to characterize desire and liking without any ontological explosion. The result is a simpler total theory of our attitude kinds and their contents than objectualism can offer.

To produce a similarly simple theory, objectualists would have to attack propositionalism on its home turf and produce an objectual account of belief. Then they might be able to defend a global objectualism as simple as propositionalism. But the prospects for a divided-attitude objectualism about belief are bleak. (Non-divided-attitude objectualism about belief looks even worse - how can objects be true or false, as belief contents should be?) Objectualists would be forced to make strange choices in characterizing beliefs concerning multiple objects. What's the object of a belief that cyanoacrylate dissolves in acetone? The objectualist will have to pick cyanoacrylate, dissolution, acetone, or some relation between them, and make it the object of something like a belief-that-it-dissolves-in-acetone. None of these options look any more appealing than the other, or do anything useful in psychological explanations. The belief-that-it-dissolves-in-acetone towards cyanoacrylate would count as different than the belief-that-cyanoacrylatedissolves-in-it towards acetone, even though these are intuitively the same belief. We saw earlier that objectualism failed to distinguish intuitively different desires. It seems now that objectualism about belief inappropriately distinguishes intuitively identical beliefs. Sticking with propositionalism about belief avoids these unattractive consequences.

Propositionalism has yet another advantage over objectualism that divides attitude kinds. Desiring-to-eat and desiring-to-wear have important similarities. They motivate action, please us when we imagine their satisfaction, and direct our attention towards their objects. Other attitudes like belief and imagination don't do these things. How should our psychological theory explain these similarities between desiring-to-eat and desiring-to-wear? Propositionalists have an answer: both are desires. Their common nature explains their common features. But according to objectualism, desiring-to-eat and desiring-to-wear are different attitude kinds, and we have no deeper psychological explanation of their similarities. Treating desire as a unified attitude 
kind explains things about all desires. Objectualists who divide attitude kinds lose this explanation.

\section{Reducing attitudes like missing, mourning, and love}

Now I'll consider some other attitudes that Brewer, Montague, and Grzankowski have presented as counterexamples to propositionalism, and suggest ways for propositionalists to respond. As they cite many examples, it's impossible to address all of them here. I hope the ones I consider will helpfully illustrate the responses available to propositionalists. For some attitudes like missing and mourning, propositional analyses may be available. While it's hard to settle the issue until we have a fuller account of love, confidence in objectualism about love isn't justified.

Montague discusses missing Athens and mourning one's brother (p. 503). She correctly notes that the contents of these attitudes can't directly be replaced by propositions - someone missing Athens doesn't miss a proposition. But attitudes like these can be analyzed in terms of propositional attitudes. Missing Athens seems to be analyzable in terms of two propositional attitudes: believing that one has left Athens and having an unsatisfied desire that one be in Athens. (This need not mean that on the whole, one desires to be in Athens. One may have conflicting desires, the preponderance of which support being away.) The way it can feel to miss Athens could then be explained by the phenomenology of unsatisfied desire. ${ }^{13}$ Even those who dispute the details of this analysis must admit that something propositional is involved in missing Athens. It essentially involves some relation to not being in Athens, rather than having one's army sack Athens or devouring Athens. Propositionalism lets us understand the relation between missing Athens and the state of affairs of not being there, while objectualism doesn't. Insofar as mourning one's brother is an intentional attitude rather than an activity, it seems to be the propositional attitude of being sad that one's brother is dead (p. 503). Mourning must be distinguished from other sad brother-related mental states, like sadness that one's brother stole one's toys. Propositionalism about mourning lets us make clear the importance of the state of affairs that one's brother is dead. In addition to specifying the boundaries of missing and mourning, these propositional analyses have the advantage of reducing them to more basic states like belief, desire, and sadness, which are useful in analyzing more of our intentional attitudes.

Brewer, Montague, and Grzankowski all discuss love. As they point out, one loves individuals rather than loving a proposition. Both of Grzankowski's forms of propositionalism and the weaker varieties of propositionalism that Brewer and Montague consider all accommodate this point, and it's one that propositionalists can happily accept. The interesting 
question is whether loving an individual is merely a collection of propositional attitudes involving relations to that individual. It's hasty to take love as a counterexample to propositionalism before we have a plausible objectual account of love that explains how lovers think, feel, and act. Until then, whether love is irreducibly objectual won't be settled. Love has important consequences for one's propositional attitudes - a lover noninstrumentally desires that the beloved be happy, and that the beloved not be destroyed. These propositional elements support the view that loving someone is having some rich collection of propositional attitudes involving the beloved. The difficulty of giving a propositional characterization of love's functional properties may be a consequence of love's complexity, not of love's including anything irreducibly objectual.

\section{A psychological conclusion}

To conclude, I'll criticize a view that underlies many of the objectualists' arguments: that the objectual structure of some of our attitude attributions is a significant reason to prefer objectualism about these attitudes. I regard it as a trivial advantage, easily outweighed by the inability of objectualism to deliver useful psychological explanations. Consider Montague's comment about the sort of view propositionalism is, and how she'll argue against it:

... propositionalism is a straightforwardly metaphysical position in the philosophy of mind, a position about the nature of intentional states. It is often discussed in specifically linguistic terms, however, and in arguing that propositionalism is false I will follow common practice in taking it that consideration of semantic and linguistic matters may have direct bearing on the metaphysical issue (p. 504).

As she notes, the question of whether our intentional attitudes have propositional or objectual content is a psychological question, not a linguistic one. It concerns the nature of human mental states. But then the methods we should use to answer it are psychological. We should prefer the theory that delivers better explanations of how we think, feel, and act. (Thagard, to his credit, argues for objectualism along these lines.) Perhaps if the evidence from psychology was ambiguous, we might reasonably turn to linguistic investigations as a second-best way to determine the nature of our intentional attitudes. And in Montague's defense, it may today be common practice for philosophers to do psychology by doing linguistic investigations of discourse about psychology. But philosophers shouldn't follow linguistic evidence to a psychological theory that can't deliver good psychological explanations.

The difference between propositionalism and objectualism in psychological explanation is stark. Propositionalism supports the psychological 
explanations we rely on, while objectualism leaves us unable to explain why people try to ride motorcycles rather than trying to eat them. Whatever advantages propositionalism has in fitting the way we sometimes talk are insignificant compared to this disadvantage. If the burden of argument is on propositionalists to defend their characterization of intentional attitude attributions that people sometimes express in an objectual form, as Montague writes, it's a burden that our only plausible option for psychological theorizing can easily bear. ${ }^{14}$

\section{Department of Philosophy \\ National University of Singapore}

\section{NOTES}

1 Brewer, T. (2006). 'Three Dogmas of Desire,' in T. Chappell (ed.) Values and Virtues: Aristotelianism in Contemporary Ethics. Oxford: Clarendon Press, pp. 253-285. Similar arguments appear in his (2009) The Retrieval of Ethics. Oxford: Oxford University Press.

2 Thagard, P. (2006). 'Desires Are Not Propositional Attitudes,' Dialogue 45, pp. 151-156.

3 Montague, M. (2007). 'Against Propositionalism,' Noûs 41(3), pp. 503-518.

4 Grzankowski, A. (2012). 'Not All Attitudes are Propositional,' European Journal of Philosophy doi:10.1111/j.1468-0378.2012.00534.x

5 Merricks, T. (2009). 'Propositional Attitudes?' Proceedings of the Aristotelian Society 109(3), pp. 207-232. Merricks argues against a stronger form of propositionalism than is defended here. Other opponents of global propositionalism include Dretske (who discusses knowledge, perception, and memory), Goldie (who discusses emotion), and Bengson and Moffett (who discuss knowledge-how). Dretske, F. (1980). 'The Intentionality of Cognitive States,' in D. Rosenthal (ed.) The Nature of Mind. Oxford: Oxford University Press; Goldie, P. (2000). The Emotions: A Philosophical Exploration. Oxford: Clarendon Press of Oxford University Press; Bengson, J. and Moffett, M. (2012). 'Nonpropositional Intellectualism,' in J. Bengson and M. Moffett (eds) Knowing How: Essays on Knowledge, Mind, and Action. Oxford: Oxford University Press.

6 Lewis, D. (1979). 'Attitudes De Dicto and De Se,' Philosophical Review 88(4), pp. 513-543. Montague and Grzankowski both cite Lewis as stating a motivation for propositionalism: it lets us see the logical relations between the attitudes, allowing us to explain inferential relations between mental states. They don't explain how objectualism can do this, and they seem not to see the significance of its inability to do so. A major dialectical purpose of this article is to demonstrate that objectualism faces deep problems in explaining inferential relations between mental states, and that an inability to do so will be devastating for the view.

7 Lewis argues that properties like 'inhabiting a world where $\mathrm{X}$ obtains' are the objects of intentional attitudes. Wishing that cyanoacrylate dissolved in acetone is wishing to have the property of inhabiting a world where cyanoacrylate dissolved in acetone (p. 529). Lewis argues against treating the objects of intentional attitudes as sets of worlds (p. 515). But his arguments permit treating them as sentential objects that can have indexical content, as many philosophers do (p. 536). As world-sized de se properties and sentential objects specify the desired relation between the agent and the object, I'm happy to consider Lewis a propositionalist. This relation is the key feature that objectual attitude ascriptions lack.

8 Schroeder, T. (2004). Three Faces of Desire. Oxford: Oxford University Press. 
9 Sinhababu, N. (2009). 'The Humean Theory of Motivation Reformulated and Defended,' Philosophical Review 118(4), pp. 465-500. I list these among the properties of desire, giving a propositionalist specification of its functional properties.

10 Schroeder, T. (2006). 'Reply to Critics,' Dialogue 45, pp. 165-174.

11 As Lewis writes, 'Uniform propositional objects ... facilitate common-sense psychology' (p. 514). I regard my examples as clarifying his point.

12 This point is put eloquently Chapter 1 of Fodor, J. (1975). Psychosemantics: The Problem of Meaning in the Philosophy of Mind. Cambridge, MA: MIT Press.

13 Montague has argued against reductionist approaches to the emotions, largely on grounds that they can't account for the phenomenology of emotion. If this is correct, objectualists will be able to protect many attitudes with an objectualist surface grammar from propositional reductions. But more attention to the phenomenology of basic propositional attitudes like desire may support reductive explanations of the phenomenology of emotion. The discussion of the phenomenology of obligation in Sinhababu, 2009, provides an example. See Montague, M. (2009). 'The Logic, Intentionality, and Phenomenology of Emotion,' Philosophical Studies 145, pp. 171-192.

14 I thank John Bengson, Ben Blumson, Talbot Brewer, Alex Grzankowski, Tanya Kostochka, Glenn Pettigrove, and two anonymous referees from this journal for comments that improved this article. 